\title{
Inside-Out-Outside-In: A dual approach process model to developing work happiness
}

\author{
Paige Williams · Margaret L. Kern · Lea Waters
}

\begin{abstract}
This conceptual paper presents the Inside-Out-Outside-In (IO-OI) model, a dual process positive systems science approach to developing work happiness. The model suggests that work happiness of employees is influenced by individual level personal resources developed through positive employee development and positive attitudes (inside-out factors), and social resources developed at the organizational level through positive strategies and positive organizational culture (outside-in factors). The model further specifies three processes that connect outside-in and inside-out factors (attitude re-evaluation, selective exposure and confirmation bias), and a series of feedback loops that support upward spirals of positive development at the individual and organizational levels. We suggest ways in which the IO-OI model can be used and tested. The IO-OI model integrates the fields of attitudes, positive organizational scholarship, and positive organizational behavior, and provides a foundation for understanding how to best foster positive attitudes, create virtuous organizations and foster employee work happiness.
\end{abstract}

Keywords: work happiness, attitudes, psychological capital, organizational virtuousness, selective exposure, confirmation bias

\section{Introduction}

Positive psychology (PP) scientifically studies flourishing in individuals, groups, and institutions (Gable \& Haidt, 2005). Much of the early research in the field was concerned with applications of PP to individuals, mostly in clinical domains (Rusk \& Waters, 2013). A recent peer-reviewed literature analysis of the field (Donaldson et al., 2014) found that this imbalance is being addressed, with more recent publications using school and work contexts in addition to clinical settings, with some focus on group level interventions. However, it is still the case that comparatively less PP research has adopted a systems approach (Kern, Sioukou, Oades \& Spong, 2016) or been conducted in the workplace (Cameron \& Spreitzer, 2011). This is despite the call in Seligman and Csikszentmihalyi's (2000) foundational article for PP to be used to promote "positive institutions" (p. 5).

Positive psychology has been criticized for ignoring the influence of organizational processes and the larger context through its focus on the individual (Kern et al., 2016; Linley, Joseph, Harrington \& Wood, 2006; Waters, 2011). This has led to calls in the literature for a more systems perspective to be taken in the application of positive psychology (Waters, 2011). The emerging field of positive systems science responds to this call and combines the strength-based lens of positive psychology with the holistic lens of systems science (Kern et al., 2016).

Emerging research into the application of positive psychology at work has been pursued in two complementary fields: Positive Organizational Scholarship (POS) and Positive

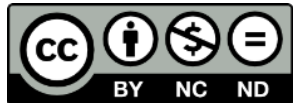

Copyright belongs to the author(s) www.internationaljournalofwellbeing.org 
Organizational Behavior (POB). POS is defined as "the study of especially positive outcomes, processes, and attributes of organizations," such as organizational virtues and peak performance (Cameron, Dutton, \& Quinn, 2003, p. 4). POB focuses upon human resource strengths and psychological capacities, such as hope, optimism, self-efficacy, and resilience (Luthans, Avolio, Avey, \& Norman, 2007; Luthans \& Church, 2002). Whereas POS typically examines organizational (macro) phenomena in a positive light, POB is concerned with the cultivation of positive psychological (micro) states. Recently, Youssef and Luthans (2011) called for a greater integration between these two fields so that leaders can gain a more thorough understanding of how to support individual and organizational growth in ways that are mutually beneficial.

The current paper adopts a positive systems science perspective and integrates the fields of POS and POB by presenting the Inside-Out-Outside-In (IO-OI) model - a process model that extends Sloan's (1987) dual intervention approach of organizational-level factors combined with individual-level factors to mutually support the development of employee wellbeing. More specifically, the new model presented in this paper suggests that: 1) particular positive attitudes provide employees with individual resources that support their work happiness, 2) virtuous organizational culture provides social and job resources that support work happiness, 3) individual level factors interact with organizational level factors, such that the positive attitudes of organization members enable them to recognize more of the virtues present in their workplace environment and make the most of the organization resources available, thus positively impacting their levels of work happiness, and 4) a number of feedback loops support these processes as self-sustaining positive energy systems. Positive attitudes of employees are changed both by organizational culture and individual focused approaches to building work happiness, and a mutually reinforcing association exists between them.

This paper fills a number of gaps in the extant literature. In examining the influence of individual-level attitudes and organizational-level culture, this paper responds to calls for positive psychology interventions to integrate across levels of analysis and also to understand the influence that the social-environmental context has over individual attitudes, behaviors, and cognitions (Linley et al., 2006). In considering inside and outside aspects of the full system, the IO-OI model answers the call to adopt a systems approach to developing wellbeing in organizations (Waters, 2011). Further, by identifying attitude development and explaining the associated processes involved, this paper responds to Lyubomirsky and Layous's (2013) call for researchers to understand more about the underlying mechanisms of PP interventions. We do this specifically within the context of positive psychology at work.

\section{Employee happiness}

In today's information and knowledge-driven society, an organization's people are critical to its innovation and performance, and, as such, provide a source of strategic competitive advantage (Bartlett \& Ghoshal, 2002; Lorange, 2005). In this context, employee wellbeing is recognized as an important outcome for organizations to develop in order to access the full capacity of their human capital (Van De Voorde, Paauwe, \& Van Veldhoven, 2012). Wellbeing at work has been defined in a number of ways, including the presence of positive experiences and absence of negative experiences (Cotton \& Hart, 2003), workplace affect and job satisfaction (Page \& VellaBrodrick, 2009), happiness within the workplace (Fisher, 2010), and more broadly as a "summative concept that characterises the quality of working life" (Schulte \& Vainio, 2010).

The current model focuses specifically on happiness, which Lyubomirsky (2007) defines as "the experience of joy, contentment, or positive well-being, combined with a sense that one's life is good, meaningful, and worthwhile" (p. 32). Although the terms "wellbeing" and "happiness" 
are used interchangeably by some researchers (e.g., Kristjanssen, 2014), others argue that they are distinct yet related phenomenon (Kashdan, Biswas-Diener \& King, 2009).

Recent developments in wellbeing theory recognize that wellbeing is a complex multidimensional construct that includes both hedonic and eudemonic elements (Ryan \& Deci, 2001; Ryff \& Singer, 2008) and is influenced by individual and contextual factors. For example, Diener et al. (2010) define wellbeing as a psychosocial construct that includes having rewarding and positive relationships, feeling competent and confident, and believing that life is meaningful and purposeful. Keyes (2002) proposes that wellbeing comprises three elements: (1) emotional wellbeing through the presence of positive emotions about oneself and one's life, (2) social wellbeing through feeling connected and valued by others, and (3) psychological wellbeing through functioning well. Seligman (2011) suggests that there are five components to wellbeing: positive emotions, engagement, relationships, meaning, and achievement. Whilst the measurement of wellbeing is criticized for being haphazard (Hone, Jarden, Scholfield \& Duncan, 2014), indicators of wellbeing can include both subjective and objective measures (for example, life expectancy), and may include assessments of behaviors and relationships as well as thoughts and feelings (e.g., the Flourishing Scale, Diener et al., 2010; PERMA-P profiler, Butler \& Kern, 2015; European Social Survey, Huppert \& So, 2013).

Definitions of happiness vary considerably (Kesebir \& Diener, 2008). Typically referred to as "subjective wellbeing" (SWB), it is broadly defined as "the extent to which people feel and think that their life is going well" (Richard \& Diener, 2009, p. 75). Schimmack (2008) defines SWB as preference-realization in that it is an indicator of the degree of realization of all an individual's preferences. Page \& Vella-Brodrick (2009) suggest that SWB is a positive state of mind associated with an individual's whole life experience, and Kashdan, Biswas-Diener \& King (2009) propose that it is an individual's "internal state that represents a variety of subjective evaluations about the quality of one's life, broadly defined" (p. 221). It is generally accepted that SWB comprises two correlated factors: 1) a cognitive evaluation of satisfaction with life, and 2) affect balance, or the frequent experience of positive emotions and infrequent experience of negative emotions (Diener, Sandvik \& Pavot, 1991; Diener et al., 1999; Schimmack, 2008). Measures of SWB are inherently subjective and generally focus on positive thoughts and feelings to assess overall satisfaction with life (e.g., Satisfaction with Life Scale, Diener, Emmons, Larsen, \& Griffin, 1985; Positive and Negative Affect Schedule, Watson, Clark, \& Tellegen, 1988). However, evidence suggests that elements of wellbeing being not directly assessed by SWB measures, (for example, relationships) strongly influence how people assess their quality of life and therefore also their levels of subjective wellbeing (Huppert \& So, 2013).

Fisher's (2010) model of wellbeing at work proposes a multidimensional construct - "work happiness" - that includes (a) engagement with the work itself, (b) satisfaction with the job, and (c) feelings of affective commitment to the organization as a whole. For our purposes here, we use this model of work happiness to operationalize the broader construct of workplace wellbeing, while recognizing that numerous other dimensions of wellbeing could be included.

Fisher (2010) argues that current workplace wellbeing measures such as job satisfaction (Locke, 1976), positive affect (Fisher, 1997), and thriving and vigor (Spreitzer \& Sonensheim, 2004) by themselves are too narrow, but together provide a better indicator of employee functioning. Together, these factors access different elements of general wellbeing theory, capturing positive emotions through job satisfaction, achievement and flow through work engagement, and relationships through affective commitment. By presenting work happiness as a higher-order construct that comprises the unique and shared variance of these three factors, Fisher suggests that workplace leaders can move beyond boosting each of the variables 
individually and capitalize on the synergistic effects that occur when the three variables come together as a whole. This enables more sustainable ways to promote work wellbeing, for if an employee is low on one aspect of work happiness (e.g., engagement) but has high levels of the other elements (e.g., satisfaction and commitment) they can still achieve work happiness. It also enables leaders to adopt a more parsimonious approach to creating the conditions for work wellbeing.

Although Fisher's model has not been fully validated, Williams, Kern, and Waters (2015) found some empirical support for it. Further, each of the elements in the model has a conceptual and theoretical evidence base. Work engagement comprises cognitive, affective, and behavioral elements in relation to an individual's performance of their job role (Schaufeli \& Bakker, 2003). Engaged employees have influence over events in their lives through their energy and selfefficacy, they create their own positive feedback through their positive attitude and activity level, and consider work to be fun (Bakker \& Demerouti, 2008; Gorgievski, Bakker, \& Schaufeli, 2010). Job satisfaction involves being content with one's job (Judge \& Kammeyer-Mueller, 2012). It includes both cognitive and affective elements, and results from an internal process of evaluating individual job facets or characteristics in a positive light. Evidence suggests that high levels of job satisfaction relate to job performance, and psychological and physical health (Faragher, Cass, \& Cooper, 2005; Judge, Thoresen, Bono, \& Patton, 2001). Affective organizational commitment is an organization member's emotional attachment to, identification with, and involvement in the organization (Meyer \& Allen, 1984). High levels of affective commitment have been related to better job performance and organizational citizenship behaviors, and lower absenteeism and intentions to quit (Meyer, Stanley, Hersocvitch, \& Topolnitsky, 2002).

Engagement, satisfaction, and commitment have generally been conceptualized as attitudes towards work. For example, a person feels they are satisfied with their job when considering the way in which their manager provides feedback and support. This requires them to think about aspects of their work in order to form the attitude, i.e., their work is the object of thought. Below, we propose that employees also have attitudes at work, such as hopeful, optimistic, resilient or confident attitudes. Moreover, we suggest that when employees experience positive attitudes at work, this leads them to have more positive attitudes towards their work. For example, an employee with an optimistic attitude at work may feel a greater sense of affective commitment to the organization because they expect that the future will go well.

\section{Developing workplace happiness}

There is increasing evidence to suggest that optimal levels of wellbeing are associated with desirable outcomes for employees and organizations. Wellbeing in employees has been related to their levels of engagement, organizational citizenship behaviors, and overall career success (e.g., Boehm \& Lyubomirsky, 2008; Harter, Schmidt, \& Keyes, 2003; LePine, Erex, \& Jonson, 2002). For organizations, employee wellbeing is linked with customer satisfaction, productivity, presenteeism, effort at work, lower voluntary turnover, and fewer absenteeism /sick days (e.g., Giardini \& Frese, 2008; Keyes, 2005; Sears et al., 2013; Wright \& Bonett, 2007). Organizations which boost employee wellbeing receive a positive return on investment through reduced absenteeism and compensation claims (PricewaterhouseCoopers, 2014). Further, there is a growing expectation from employees that organizations will take an active role in supporting their wellbeing, and this has become an important point of competitive advantage for organizations in the employment market (Martin et al., 2005). As such, it is in the interest of organizations to intentionally support employee wellbeing. 
Organizational change literature suggests that change - such as shifting a workplace to support employee wellbeing - can be considered "top-down" if initiated from the top of the organization through planned changes (Lewin, 1946), or "bottom-up" if initiated from the bottom of the organization through emergent changes (Burnes, 1996, 2004). Further, Sloan and Gruman (1988) suggest that organizational-level factors, such as climate, influence outcomes and participation in workplace wellbeing programs as much as individual-level characteristics of employees such as gender and personality (see Figure 1.) As such, Sloane (1987) proposes that a dual approach that addresses both organizational and individual factors is required for interventions aiming to foster employee wellbeing at work.

\section{Figure 1. A dual approach to supporting employee participation in workplace health promotion programs (Sloan \& Gruman, 1988)}

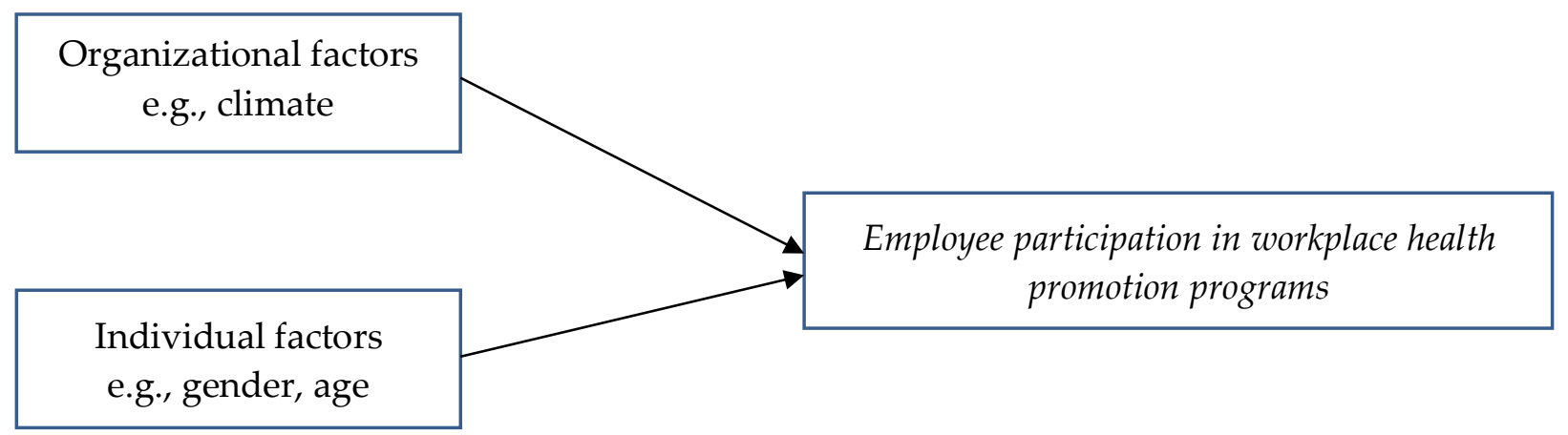

Based on this, the IO-OI conceptual model builds on both top-down organizational level and bottom-up individual level factors that influence employee wellbeing at work. However, we suggest that the current language is limiting. For example, an organization-wide training program about gratitude in the workplace may be offered to employees. This is considered a "top-down organizational level" change initiative. As a result of the training, employees may develop new attitudes and behaviors (individual level) that positively influence their workplace climate (organizational level). A work team may then decide to create a gratitude wall in their workspace or begin their weekly team meetings with gratitude stories, thus changing the physical environment and processes in the workplace through "bottom-up employee level" initiatives. Thus, while the original training initiative was top-down and aimed at the organizational level, the outcomes and initiatives have been at the individual and group level, and are considered bottom-up.

We believe a more accurate way of describing these factors is by positing that work happiness is influenced by factors "outside" of the employee and factors "inside" the employee. We define outside factors as those that are in the broader work environment that influence an employee's experience of work, such as the organizational culture, work climate, job characteristics, managers/supervisors, colleagues, and physical work environment. We define inside factors as those that influence an employee's experience of work and that cannot be separated from the individual, such as values, beliefs, attitudes, emotions, and behaviors. 
Figure 2. The Inside-Out-Outside-In (IO-OI) model: A dual approach process model to developing happiness at work

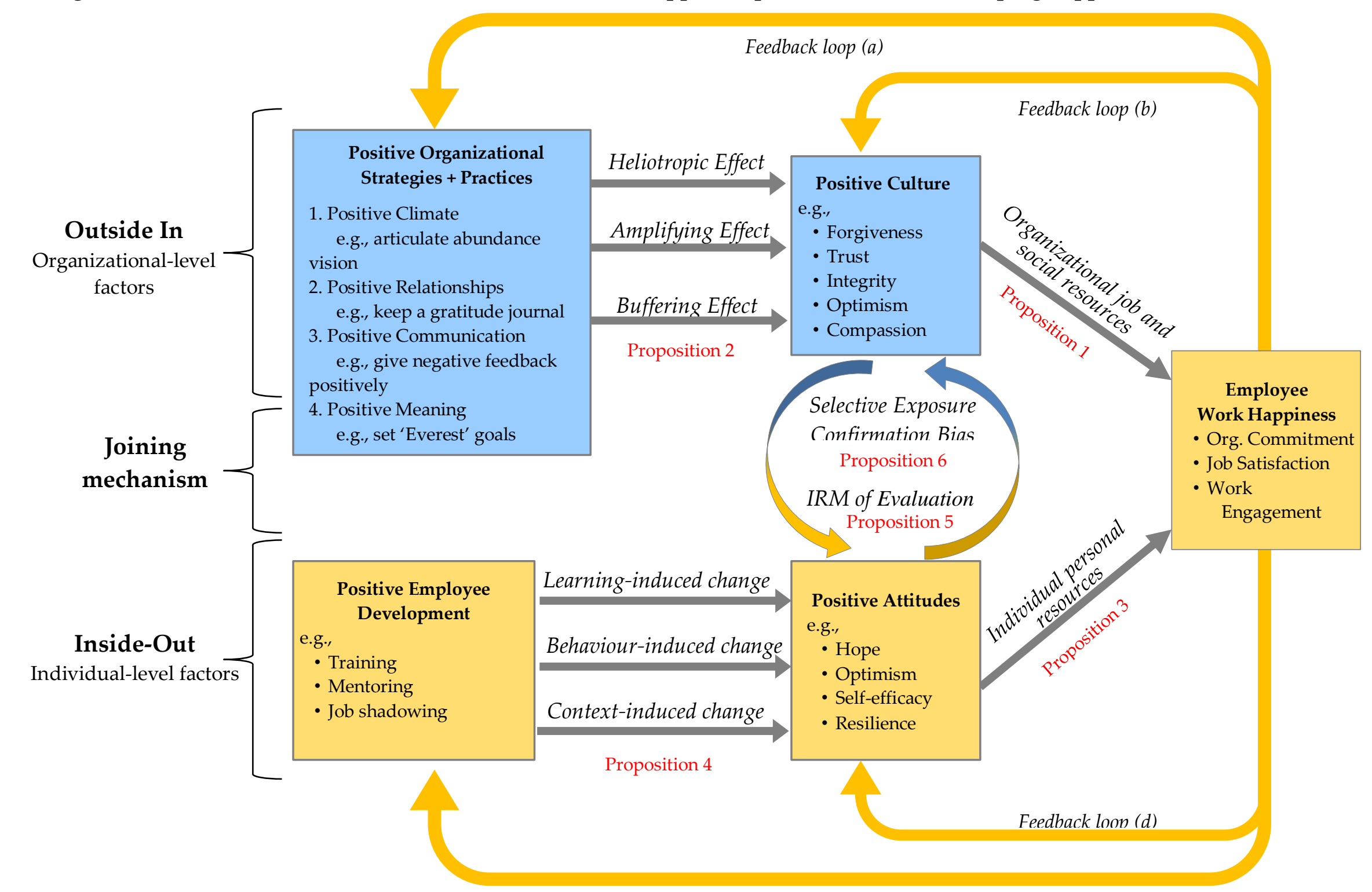

Feedback loop (c) 
Thus, it is the locus of change being targeted by an intervention to develop work happiness that determines whether an organization is taking an "outside-in" or "inside-out" approach. For example, an initiative such as an employee coaching program is an inside-out approach, as the locus of change is the employee's mindset, thoughts, feelings and behaviors. An initiative such as an employee starting a gratitude board is an outside-in approach, as the locus of change is in the work environment. We also suggest that factors outside and inside the employee will have a mutually influencing relationship. Thus, both an "outside-in" and an "inside-out" approach will individually and synergistically impact work happiness (i.e., attitudes of engagement, satisfaction and commitment toward the organization) and may be initiated from the top-down or bottom-up.

Figure 2 shows the full IO-OI model and depicts the interrelationships proposed between an outside-in approach of developing job and social resources through virtuous organizational culture and an inside-out approach of developing personal resources through fostering positive attitudes in employees. The model also presents a number of important feedback loops that support the IO-OI model as a self-sustaining positive energy system. Using the outcome of interest - work happiness - as the start point, the remainder of this paper unpacks the IO-OI model via six propositions. We first explain the outside-in organizational level factors (propositions 1 and 2) and then move to the inside-out individual level influences (propositions 3 and 4). Finally, we explain the joining mechanisms between inside-out and outside-in processes (proposition 5) and their influence on work happiness (proposition 6).

\subsection{Outside-in}

\subsubsection{Organization culture and work happiness}

Proposition 1: Employee work happiness is supported through organizational social resources provided through a culture of virtuousness.

Growing evidence indicates that organizational culture has a critical influence on employee wellbeing (Chang \& Lu, 2007; Hartel \& Ashkanasy, 2011). Organizational culture can be defined as the unique pattern of shared values, beliefs, and assumptions of employees about an organization learned through past experiences that is manifest through observable artifacts, espoused values, collective behaviors and shared beliefs (Schein, 1980). For example, in a workplace with a culture of safety, safe work procedure signs are displayed in the workplace (observable artifacts). Formal organization communication such as newsletters and annual reports provide metrics such as the number of days without a safety incident (espoused values). Safety is frequently the direct topic of conversations in the workplace and underlies many others (shared beliefs). And through their individual job roles, everyone in the organization is working to achieve exemplary standards of safety across all aspects of the organization (collective behaviors).

Organizational culture can range from being hostile and destructive to flourishing internally and externally. Organizations with constructive culture orientations promote social support, participation, teamwork, constructive interpersonal relations, and self-actualization, whereas destructive culture orientations foster competition, oppositional relational styles, and avoidance (Cooke \& Roussea, 1988). Constructive cultures are best espoused by a virtuous culture, in which "employees collectively behave in ways that are consistent with the best of the human condition and the highest aspirations of human kind" (Cameron \& Winn, 2012, p. 235).

Virtues at the individual level are considered to be positive traits that represent the best of the human condition - such as hope, optimism, kindness and curiosity - which are valued across 
time and culture (Peterson \& Seligman, 2004). Extending virtues to the organizational level, Cameron, Bright, and Caza (2004) suggested a five-factor model of organizational virtuousness comprised of 1) organizational forgiveness, through which mistakes are quickly forgiven and used as opportunities for learning; 2) organizational trust, in the courtesy, consideration and respect enacted in the organization and the mutual trust between peers and leaders; 3 ) organizational integrity, demonstrated by the honesty, trustworthiness and honor that pervade the organization; 4) organizational optimism, in the belief of organizational members that they will succeed in doing well even in the face of challenges; and 5) organizational compassion, through the common acts of compassion and concern that show that people care about each other. A culture of organizational virtuousness is one that embodies these five values of forgiveness, trust, integrity, optimism, and compassion at the organizational level (rather than within individual employees).

As one type of workplace culture, organizational virtuousness (OV) manifests through observable artifacts, espoused values, shared beliefs, and collective behaviors. For example, virtues-based practices such as gratitude boards (to support compassion and optimism) or leaders beginning meetings with a "what went well" exercise (to support optimism and trust) provide observable artifacts of a virtuous culture. Such practices also provide opportunities to foster virtues throughout the organization as a shared set of values is espoused. Other elements of culture, such as shared beliefs and collective behaviors, may be influenced by embedding virtues in organizational behaviors and leadership, engaging in strengths-based performance conversations, and infusing virtues into training, development and coaching (Bouskila-Yam \& Kluger, 2011; Cameron et al., 2011).

A virtues-infused culture may also provide job and social resources that influence the quality of relationship within organizations, such that employee work happiness increases. For example, a workplace culture in which leaders are optimistic about the future, compassionate in their communication, and forgiving when needed, may help develop supportive leader-worker relations and a supportive work community. Leaders with high levels of gratitude may be more likely to enact the company's recognition and reward programs, thus enhancing employee happiness. A culture in which there are high levels of integrity and trust between colleagues will enable regular and transparent feedback. Evidence suggests that social resources within organizations, such as support from colleagues, newcomer socialization and perceived organizational support, relationships with co-workers and supervisors, and leadership enacted with consideration, are antecedents to work happiness (Bakker \& Demerouti, 2008; Judge \& Kammeyer-Mueller, 2012).

\subsubsection{Positive organization strategies and virtuous organization culture}

Proposition 2: Positive strategies and practices increase the presence of virtues within the organization through heliotropic, amplifying, and buffering effects.

Working backwards from organizational virtuousness to positive organizational strategies (see Figure 2), we suggest that Cameron's (2013) positive organizational strategies framework may be used by leaders to systematically and strategically support a more virtuous work culture. The framework encourages leaders to put in place four positive strategies: 1) Positive climate: Create a culture of abundance, by building the collective capacities of organization members; 2) Positive relationships: Develop positive energy networks that unlock capacity and resources within individuals and the organization to perform, create, and persist; 3) Positive communication: Deliver negative feedback positively so that relationships build and are strengthened; and 4) 
Positive meaning: Set Everest goals, which represent the peak achievement for an organization with a moral purpose and meaning.

Each strategy has specific positive practices designed to develop more collective virtues and influence the attainment of a positive culture (Cameron, 2013). For example, under the positive climate strategy of creating a culture of abundance, leaders can engage in the specific positive practices of articulating a positive vision and generating commitment. Under the positive relationships strategy of developing positive networks, activities can include mapping positive energy networks and keeping a gratitude journal. To enact the positive communication strategy, when delivering feedback, leaders can focus on problems, rather than personal attributes, and role model honesty and genuineness. Finally, in the positive meaning strategy of setting Everest goals, positive practices include using SMART (specific, measureable, achievable, realistic, timely) goal attributes and identifying "abundance gaps" by determining what signifies positively deviant performance (i.e., that which is significantly above the norm, in comparison to current performance).

Three sub-processes have been proposed to explain the relationship between positive organizational strategies and virtuousness in the organization culture. The first is the heliotropic effect, defined as the instinct in all living systems to move towards positive energy and away from negative energy (Cameron at al., 2011). For example, in setting Everest goals, organizational members are asked to focus on affirming practices that create positive, life-giving energy at work. Collective efforts to achieve Everest goals bring to life virtues such as optimism for the future, trust in colleagues to fulfill their commitment to the goal, and forgiveness when plans go astray.

The second sub-process is the amplification effect, which suggests that positive strategies and practices create self-reinforcing positive spirals through increasing positive emotions, social capital, and pro-social behaviors that lead to the development of a virtues-based culture (Cameron et al., 2004). For example, Cameron and Plews (2012) provided a case study of the implementation of positive practices at Prudential Real Estate and Relocation (PRER). CEO Jim Mallozzi asked his senior management team to identify three things that they valued about three other members of the team and tell those people about them. In doing this, the group articulated the attributes, capacities, and strengths of the people in the room, generating the belief that they could succeed in doing well even in the face of the current business challenges. They turned this belief into action by inviting individuals to share a current business problem that they were trying to solve, and the rest of the group offered ideas and support to help solve it. This, in turn, increased optimism in the group, which was expanded through the rest of the organization as the ideas were put into action and members saw the business benefit of their thinking. Thus the virtue of optimism was amplified through the adoption of positive practices that lead to selfreinforcing positive spirals and cultural change, as these virtues were spread into the culture of the organization through beliefs, behaviors, values, and artifacts.

The third sub-process is the buffering effect, in which positive strategies and practices provide buffering effects to the organization by increasing resiliency, solidarity and a sense of efficacy (Cameron, Bright \& Caza, 2004; Cameron et al., 2011) that support a virtues-based culture. For example, in a study by Cameron et al. (2004) of approaches to downsizing, they identified that Southwest Airlines adopted positive strategies and practices in the economic aftermath of the U.S. terrorist attacks on September 11, 2001. By continuing an un-matched industry record of not downsizing, Southwest Airlines CEO Jim Parker publicly announced that the company was prepared to suffer financial damage to protect their peoples' jobs. This was an explicit and public commitment to employees, demonstrating the virtues of integrity and optimism. These positive practices led to trust and forgiveness from the staff, an increased sense of security, and easier 
union negotiations that further reinforced the virtues and resulted in better objective performance (e.g., productivity, stock value) and perceived performance (e.g., staff turnover) in the mid to long term.

\subsubsection{Discussion}

In sum, factors outside of the employee such as organizational culture and positive practices influence their levels of work happiness. It is suggested that a virtuous culture provides job and social resources that support employee work happiness, and that leaders may use specific positive strategies and practices to develop a culture of virtuousness.

While the outside-in approach to work happiness is important, we argue that it is necessary but not sufficient, for three reasons. First, past research shows that organizational approaches to cultural change are slow (Cameron, 2008). Second, organization level culture change initiatives are open to a wide variability in delivery, uptake, and commitment from management and employees (Todnem By, 2005). Whilst some leaders may support the practices, others may not, thereby under-mining efforts to reach a "tipping point" in the collective behaviors within the organization. Third, positive practices are external to the employee; they do not require internal re-evaluation of attitudes (defined as beliefs, feelings and/or behaviors) and could be viewed as "just another policy initiative".

Beyond these three difficulties in cultural change, we also believe that, even when cultural change is successful and a virtuous culture is developed, this still may not lead to work happiness. We propose that it is not simply the presence of virtues that matters, but that to benefit happiness, employees need to notice and evaluate the virtues present in the culture. For example, a team with a positive culture might still have members who fail to see the virtues around them, and resist or even impede positive practices such that the presence of virtues has no impact on their happiness.

\subsection{Inside-out}

We now move to the lower half of the IO-OI model (Figure 2), to look at the inside-out factors that influence work happiness. Earlier we proposed factors "outside" the employee such as organizational job and social resources support work happiness. Evidence suggests that beyond the outside factors described in part 1 , there are also factors within the employee that influence happiness, such as attitudes, positive affect, and core-self evaluations (e.g., Hobfoll et al., 2003; Judge \& Kammeyer-Mueller, 2012).

\subsubsection{Employee attitudes}

One factor that influences an individual's capacity to evaluate the presence of virtues in the workplace culture is their attitudes. Attitudes can be defined as "an evaluation of an object of thought" (Bohner \& Dickel, 2011, p. 392). One function of attitudes is to help us navigate our environment effectively and efficiently by removing the need to evaluate and make decisions about each new object encountered (Katz, 1960). Attitudes help assimilate new knowledge and have been found to help categorize objects, and support decision-making ease and decisionmaking quality (e.g., Katz, 1960; Azjen, 2001; Blascovich et al., 1993; Fazio et al., 1992; Smith et al., 1996). Further, positive attitudes towards work (such as satisfaction, engagement and commitment) have been found to influence outcomes such as intention to quit, in role and extra role performance, client satisfaction, proactivity, adaptability, and creativity (Mobley, Rothbard, \& Patil, 2012). 
Historically a tripartite view of attitudes held that they are formed and manifest through three components - beliefs, feelings, and behaviors (Eagly \& Chaiken, 1993) and that all three components must be present and consistent for the attitude to exist (Rosenberg \& Hovland, 1960). Research by Zanna and Rempel (1988) re-examined these assumptions and proposed a more nuanced view, in that attitudes can be established and enacted through any of the three pathways.

The cognitive pathway to attitude formation is driven by an individual's beliefs about whether an attitude object is (un)desirable or will lead to (un)desirable outcomes. The expectancy-value model (Fishbein \& Ajzen, 1975) is an example of this approach. It proposes that an attitude towards an object is formed by estimating the probability that the object has particular attributes, and multiplying this by the value the individual places on it to give an "expectancyvalue". By totaling all of the "expected-values," the individual arrives at an overall attitude towards the object.

The affective pathway depends upon how an attitude object makes us feel. There are three primary ways through which this may occur. First, in operant conditioning, attitudes that lead to positive (negative) outcomes are more (less) likely to be repeated (e.g., Hildum \& Brown, 1956). Second, in classical conditioning, attitudes are formed non-consciously through an individual attending to differences between attitude objects in their environment and making associations between them. For example, an attitude object such as a brand of clothing might be paired with another object such as young attractive models, resulting in a positive affective response and the formation of a positive attitude about that object. Third, in exposure, greater contact with an attitude object makes it more accessible to perception and increases liking for it (Zajonc, 1968).

The behavioral route to attitude formation arises when one has had experience with an attitude object without clear feelings or beliefs, and attitudes can be inferred by the individual attitude holder from their past behavior (Bem, 1967; Fazio \& Olson, 2007). For example, an individual may have voluntarily attended a workplace training session without being clear or conscious of their beliefs and/or feelings about it, but in retrospect can reason that they have a positive attitude towards their own development and training generally.

This integrative view of the cognitive, affective and behavioral elements of attitudes is supported in the MODE (Motivation and Opportunity as DEterminants) model, in which attitudes are understood to be associations between an evaluation and an object stored in memory, and these associations can be based on cognitive, affective and/or behavioral knowledge from which a "summary" evaluation is reached (Fazio, 1990; Fazio 2000).

\subsubsection{Positive employee attitudes and work happiness}

\section{Proposition 3: Employee work happiness is supported through individual personal} resources provided by positive attitudes.

The attitudes of organization members assist them to evaluate the behaviors of colleagues and managers, as well as organization policies, their job role, and the organization as a whole. They also influence member thoughts, feelings, and behaviors whilst at work. Attitudes were defined earlier as "an evaluation of an object of thought," thus we define a positive attitude as "a positive evaluation of an object of thought". As we explain below, the development of specific positive attitudes is likely to increase personal resources, such as the frequency of positive affect, positive core-self evaluations linked to resiliency, and an individual's sense of their ability to successfully control their environment, and, in doing so, develop member work happiness.

In the positive organizational literature, psychological capital (PsyCap) has been identified as a foundational evidence-based framework that leaders can use to develop the positive 
psychological capacities of organization members (Luthans, Youssef, \& Avolio, 2006). PsyCap is defined as "an individual's positive psychological state of development" (Luthans, Youssef, \& Avolio, 2007, p. 3) and comprises four elements: hope, efficacy, resilience, and optimism, which have been shown to lead to higher performance outcomes in the workplace (Luthans, Avey, Avolio, \& Peterson, 2010).

PsyCap has traditionally been considered a "resource bank" that enables successful performance and response to challenges or events, and that supports people to flourish, and to have success in multiple life domains, including work, relationships, and their health (Hobfall, 2002; Lyubomirsky, 2005). However, we propose that in addition to its function as a resource bank, PsyCap can also be conceptualized as a positive attitude. We do this for five reasons. First, the mechanisms that are proposed to underlie the synergy between the elements of PsyCap (Luthans et al., 2010) also reflect the ways in which attitudes are formed, influenced and manifested, i.e., through an individual's thoughts, feelings, and behaviors. Second, the cognitive, affective and conative processes through which it is proposed that PsyCap influences wellbeing (Youssef-Morgan \& Luthans, 2014) mirror the influence and manifestation of attitudes in thoughts, feelings and behaviors. Third, the suggestion that PsyCap fosters "the formation of positive appraisals of past, present and future events" (Youssef-Morgan \& Luthans, 2014, p. 185) suggests that not only is PsyCap a resource but that it is also an attitude, and, more specifically, a positive attitude, because in either conceptualization - as a resource or an attitude - it involves an evaluation of an object of thought in the form of a positive appraisal. Fourthly, the argument of PsyCap as "state-like" and manageable and open to development (Youssef-Morgan \& Luthans, 2014), mirrors those of attitudes, which are also believed to be open to development (Cunningham et al., 2007). Finally, the implicit PsyCap scale (Harms \& Luthans, 2012) which measures less conscious levels of PsyCap, suggests that it is a construct that can be understood as an attitude, given that attitudes have an implicit aspect to them. As such, we operationalize positive attitudes here as PsyCap.

The four attitudes of PsyCap have been found to be open to development and impacted through work-based interventions (Youssef \& Luthans, 2007), suggesting that it is a valid model for leaders wanting to create effective employee change. For example, Luthans, Avey, Avolio, and Petersen (2010) tested a PsyCap intervention with 80 managers. The two-hour intervention comprised a series of targeted exercises designed to develop each of the four PsyCap sub-factors, and integrative reflective exercises to enable understanding an operationalization of the higherorder PsyCap construct. PsyCap scores increased, and their self-rated and manager-rated performance also significantly increased.

The four positive PsyCap attitudes may also be built upon through workplace triggers such as the positive strategies and practices mentioned earlier (Cameron, 2013), and in doing so, develop individual personal resources. For example, the positive practice of providing negative feedback in a positive way requires a leader to have efficacy in their communication skills (positive core-self evaluations) and optimism in the expectation that their desired outcomes will be achieved through the discussion (positive affect). It requires the organization member receiving the feedback to have a resilient attitude to failure, and hopeful, optimistic attitudes to overcoming the problem and improving their performance (positive affect and positive core-self evaluations). Thus, positive PsyCap attitudes may provide both organization members and leaders with personal resources that enable and support their work happiness.

We therefore propose that the PsyCap framework can support organizations to develop four specific positive attitudes: hope, optimism, self-efficacy, and resilience. A hopeful attitude is one in which organization members have high levels of agency (goal-directed energy) and can 
generate pathways and planning to meet their goals (Snyder et al., 1991). An optimistic attitude involves a positive future expectation (Scheier \& Carver, 1985). Self-efficacious attitudes comprise an individual's confidence in their motivation, skills, and cognitive resources to successfully meet the demands made of them (Stadjkovic, Luthans, \& Slocum, 1998). An attitude of resilience is characterized by the ability to "bounce back" from challenging situations (Masten \& Reed, 2002).

\subsubsection{Fostering positive attitudes}

Proposition 4: Positive employee development (e.g., training, mentoring, job shadowing) fosters positive attitudes by triggering learning-induced, behavior-induced, and contextinduced attitude change.

The formation of attitudes is considered a critical adaptive capacity. Of equal importance is that attitudes can be changed in light of new information and experiences (Bodenhausen \& Gawronski, 2013). Three theories are proposed regarding the mechanisms involved in attitude change to explain the link between positive employee development and positive attitudes: learning-based; behavior-induced and context-induced (Bodenhausen \& Gawronski, 2013).

First, learning-based theories involve cognition and affect, and suggest that learning new information about an attitude object (cognition), paired with a positive emotional response (affect), drives observed attitude change. Learning can be propositional, in that new information is proposed about an attitude object, or it can be associative, such that new "pairings" of associations between attitude objects are made. Classical conditioning theory (Pavlov, 1927/1960) suggests that the acquisition of new information about an object leads to attitude change, further, that new links can be established between attitude objects in memory based on co-occurrences between objects and events (Baeyens et al., 1992). For example, a part-time employee may need to attend a first-aid training workshop that is being run outside of their normal working hours. As such, their attitude towards attending the workshop is negative and their attitude about the organization is that part-time employees are not valued or considered. They then learn that a second workshop has been organized at a time that is convenient for part-time employees, and that part-time employees will have first refusal to attend this workshop (new information). As a result, the employee's attitude towards the workshop becomes more positive, as does their association between their current organization and part-time employees.

Second, behavior-induced attitude change examines the influence of an individual's behavior on the evaluation of an attitude object. For example, an employee may attend a training workshop because it is compulsory, and the act of attending engenders positive attitudes towards the workshop. Cognitive dissonance theory suggests that inconsistencies between cognitions and behaviors motivate an individual to find consonance, which, if it cannot be found through external factors, will lead to a change in attitudes (Festinger, 1962). Bem's (1967) selfperception theory assumes that individuals make inferences about their attitudes from their past behavior. For example, if they attended a non-compulsory workshop, they are likely to conclude that, "If I attended the training workshop without an external justification, then I must hold an internal attitudinal reason for doing so."

Third, context-induced attitude change recognizes the significant influence that contextual cues can have in object evaluation. An individual may have extensive and diverse knowledge about many attitude objects; it is unlikely that all of this will be accessed at the point of evaluation, and the specific knowledge subset that is activated, based on contextual cues, may lead to very different evaluations (Tourangeau \& Rasinski, 1988). For example, an employee is considering whether to attend a training workshop. Through a conversation with a colleague, 
they are prompted to consider the benefits they will gain from it, rather than the work that they could be doing during that time instead (contextual cue). Cognitive dissonance theory suggests that their attitude may become more positive toward the workshop because they will need to resolve the dissonance created by focusing on the benefits of the training in the conversation.

In summary, a number of mechanisms are shown to be involved in attitude change: learning processes stimulate change in beliefs and feelings through the acquisition of new information or associations about an attitude object, an individual's behavior can lead to a re-evaluation of attitudes, and the context of an attitude evaluation can influence different knowledge subsets being accessed, resulting in varied evaluations about the same attitude object. Any one of these processes may result in changes to cognition (beliefs), affect (feelings), and/or behavior.

We propose that engaging organizational members in positive development such as training, mentoring, and/or job shadowing can aid the development of positive attitudes by impacting one or more of these three attitude change mechanisms. For example, a PsyCap training program might provide contextual cues that focus employees on their attitude. As part of the training, an employee may set a goal of completing a gratitude journal every day for two weeks (behavioral change). By noticing positive aspects of their work environment (cognitive change) for which they feel grateful (affective change), positive attitude changes occur, as the employee develops an "attitude of gratitude."

\subsection{Connecting inside-out and outside-in factors}

We have explored organizational factors that support work happiness (outside-in) such as virtuous organizational culture, and internal factors that influence work happiness (inside-out), such as positive employee development and positive attitudes. We now consider three mechanisms that may link the inside-out and outside-in factors: 1) the iterative reprocessing of evaluations (proposition 5), 2) selective exposure, and 3) confirmation bias (proposition 6).

\subsubsection{The Iterative Reprocessing Model}

Proposition 5: Individual attitudes iteratively combine with evaluations of the organization environment in either a positive way that supports work happiness, or a negative way that hinders work happiness.

We suggest that the Iterative Reprocessing Model (IRM; Cunningham \& Zelazo, 2007; Van Bavel, Xiao, \& Cunningham; 2012), provides a lens for understanding how a virtuous culture (outside) influences employee positive attitudes (inside). According to the IRM, an attitude object (e.g., a new company policy) triggers an evaluative cycle through which lower-order, automatic (or implicit) stored evaluations influence and are influenced by higher-order, reflective (or explicit) real-time processes. This leads to a dynamic evaluation of the attitude object that combines associations stored in memory with current information to create a positive or negative attitude toward that object. As such, any single evaluation represents the current processing state of a greater evaluative system, which is influenced by those elements of the stored attitude that are currently active and by the level of reflective processing that takes place. As illustrated in Figure 3 , each iterative cycle of evaluation is influenced by new contextual or motivational information, which creates a new evaluation of the attitude object that takes into account finer attitude-object detail, the context, and/or current goals. 
Figure 3. The iterative cycle of evaluation (adapted from Cunningham \& Zelazo, 2007)

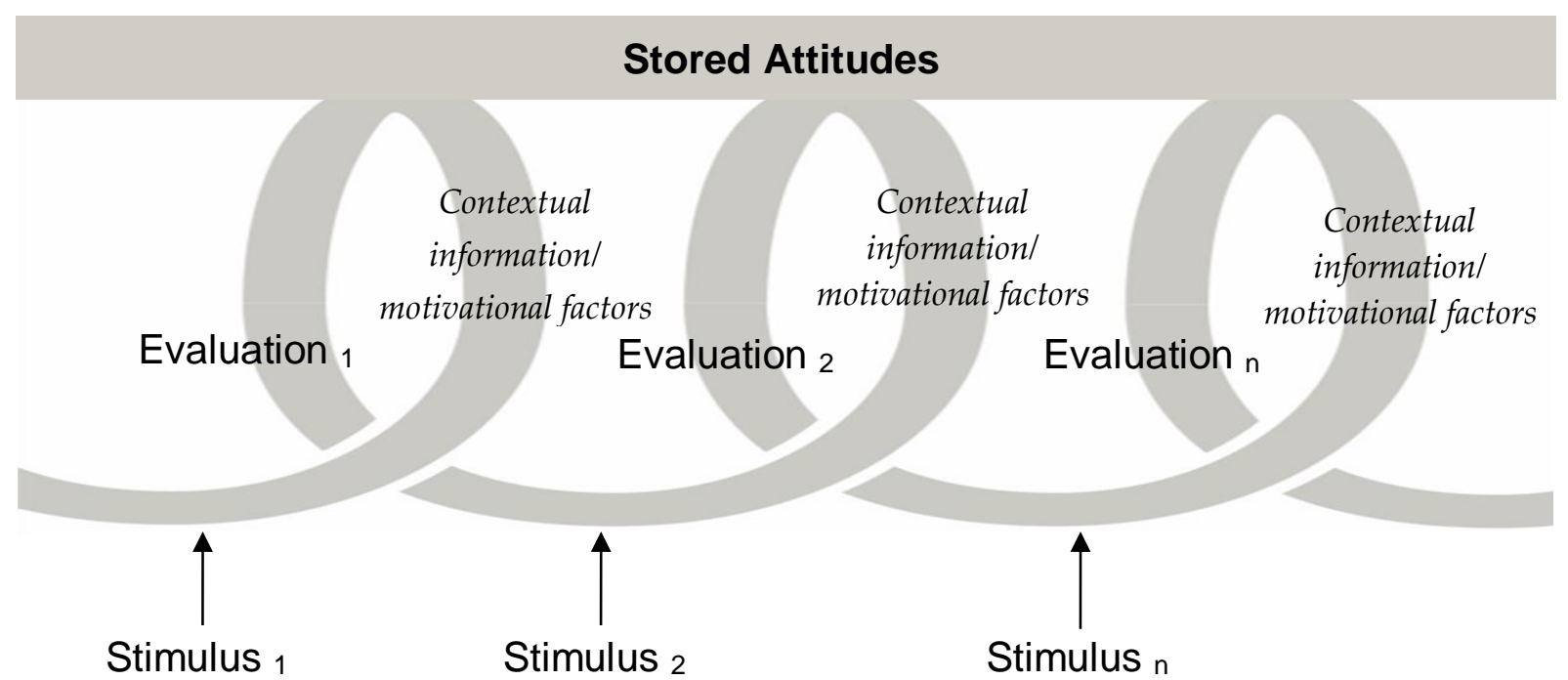

\section{Time}

For example, consider the scenario where an employee has a pressing project deadline. Their stored attitude associated with deadlines is that all deadlines are stressful. However, this may be altered in this specific instance if the department manager adds extra staff and resources to the project. The actions of the manager lead to the attitude-object relationship becoming more specific, and the employee's stored attitude that deadlines are stressful becomes more nuanced for this specific deadline, which has become less stressful. Hence, while our automatic, stored (implicit) attitudes help us to make quick assessments, these attitudes are dynamic and can be altered when the context or goals change, through the influence of reflective (explicit) real-time processes.

The number of times an attitude object goes through the iterative process depends on personal and situational variables such as cognitive ability, motivation, and opportunity (Fazio, 1990). Thus, evaluations may be formed very quickly and remain stable for a time, or they may go through many iterative cycles over a long period of time and be continually altered and updated. Increasing reflective processes in individuals enables the more nuanced and/or goal congruent evaluations needed to navigate complex environments, self-regulate and appraise abstract concepts such as virtues in the organization culture (Van Bavel, Xiao, \& Cunningham, 2012).

We propose that employee development to foster specific positive attitudes can trigger a positive iterative evaluation cycle by providing new motivational information with which members can re-evaluate their stored attitudes. In parallel, virtues in the organizational culture enabled through positive practices may provide new contextual information that keep virtuous cues in their organizational environment (OV) as the active process. Thus a positive cycle of evaluation and attitude change may result, as positive individual attitudes are fostered through positive employee development and motivation, and are supported and reinforced by positive context cues in the organizational environment (OV). We propose that this ongoing positive spiral may, in turn, lead to higher levels of employee work happiness. Equally, we surmise that the IRM can work in a negative cycle, such that when positive attitudes (PsyCap) are not 
supported and reinforced by positive context cues in the organizational culture (OV), employee work happiness decreases.

As an example, employees may have a new manager transfer from another department. Team members may have heard negative rumors about the manager, such that they have a negative attitude towards the manager. Although the manager does positive and constructive actions during the first week, the employees observe one situation where she becomes frustrated, which reinforces a negative attitude about the manager. An employee might feel dissatisfied with the manager, disengaged with their work, and less committed to the organization as a whole. However, over the next few weeks, the manager acts in many virtuous ways, which causes dissonance between the team members' initial negative evaluation and the reality of her management style. This triggers an evaluative iteration within the team members to resolve the conflict between their stored evaluation and the virtuous behavior being shown by the manager. In doing so, the evaluative cycle provides the opportunity for the relationships to develop more positively. As attitudes shift, affect improves, ultimately increasing team members' work happiness.

\subsubsection{Selective exposure and the confirmation bias}

Proposition 6: Selective exposure and confirmation biases allow employees with positive attitudes to notice and evaluate practices and virtues present in the organization environment in a more positive light, resulting in greater work happiness.

Inner attitudes and outer aspects of the organization are further connected by what an individual subconsciously and consciously gives attention to. Selective exposure is the phenomenon whereby people focus on information in their environment that is congruent with and confirms their current attitudes (Klapper, 1960). It has been found to have influence in a wide range of contexts, including attitudes to media use (Stroud, 2007) and decision making (Fischer et al., 2010), and is acknowledged as being relevant to organizations (Kastenmuller et al., 2010). Klapper (1960) suggests that selective exposure comprises three processes: 1 ) selective exposure, in which people avoid communication that is opposite to their existing attitude; 2) selective perception, in which, when confronted with material that opposes their viewpoint, people either do not perceive it or they make it fit for their existing opinion; and 3) selective retention, in which people simply forget attitude-incongruent information. For example, imagine the previous situation with the new manager; team members with positive attitudes are less likely to join in the negative gossip about the manager (selective exposure), they will explain away the incident of frustration as being a "one-off" (selective perception) or they may forget that it happened at all (selective retention).

Individuals may also actively seek out, remember and assign more weight or validity to information that supports their current attitude. This is known as confirmation bias and refers to "unwitting selectivity in the acquisition and use of evidence" (Nickerson, 1998, p. 175). Confirmation biases have been shown to be pervasive across a variety of contexts, including politics (Tuchman, 1984), science (Hergovich, Schott, \& Burger, 2010), and law (Pennington \& Hastie, 1993). A number of theories are proposed to explain confirmation bias, including the desire to believe information that is more pleasing or the "Pollyanna" principle (Matlin \& Stang, 1978), limits to individual information-processing capacity i.e., the ability to consider only one option at a time (Doherty \& Mynatt, 1986), and positive-test strategy or positivity bias, in which individuals find it easier to process confirmatory rather than opposing information (Heider (1958). As an example and to continue the scenario above, the information that the team members have taken in about the new manager through the processes of selective exposure (i.e., the 
manager's virtuous behavior) may be recalled more easily, assigned more weight and given higher levels of validity than the negative rumors. This will confirm their earlier evaluation that she is a good manager, and in doing so, increase team members' work happiness.

The processes of selective exposure and confirmation bias thus impact what an employee sees, pays attention to and interprets in their environment. It is likely that employees with positive attitudes have greater accessibility to spotting the virtuous behaviors of others and the positive practices put in place by an organization because these features of the work environment are attitude-congruent (selective exposure), and seem valid (confirmation bias). Figure 4 demonstrates the interactive loop that in theory stems from positive employee development. However, this loop does not just occur during employee development. Rather, the loops are likely to continue to occur over time as selective exposure and confirmation bias influence the attention and weight people give to virtue opportunities present in an organization over time (e.g., positive practices and other displays of virtue).

\section{Figure 4. The processes and outcomes of positive development on employee attitudes and evaluation of virtues in the organization culture}

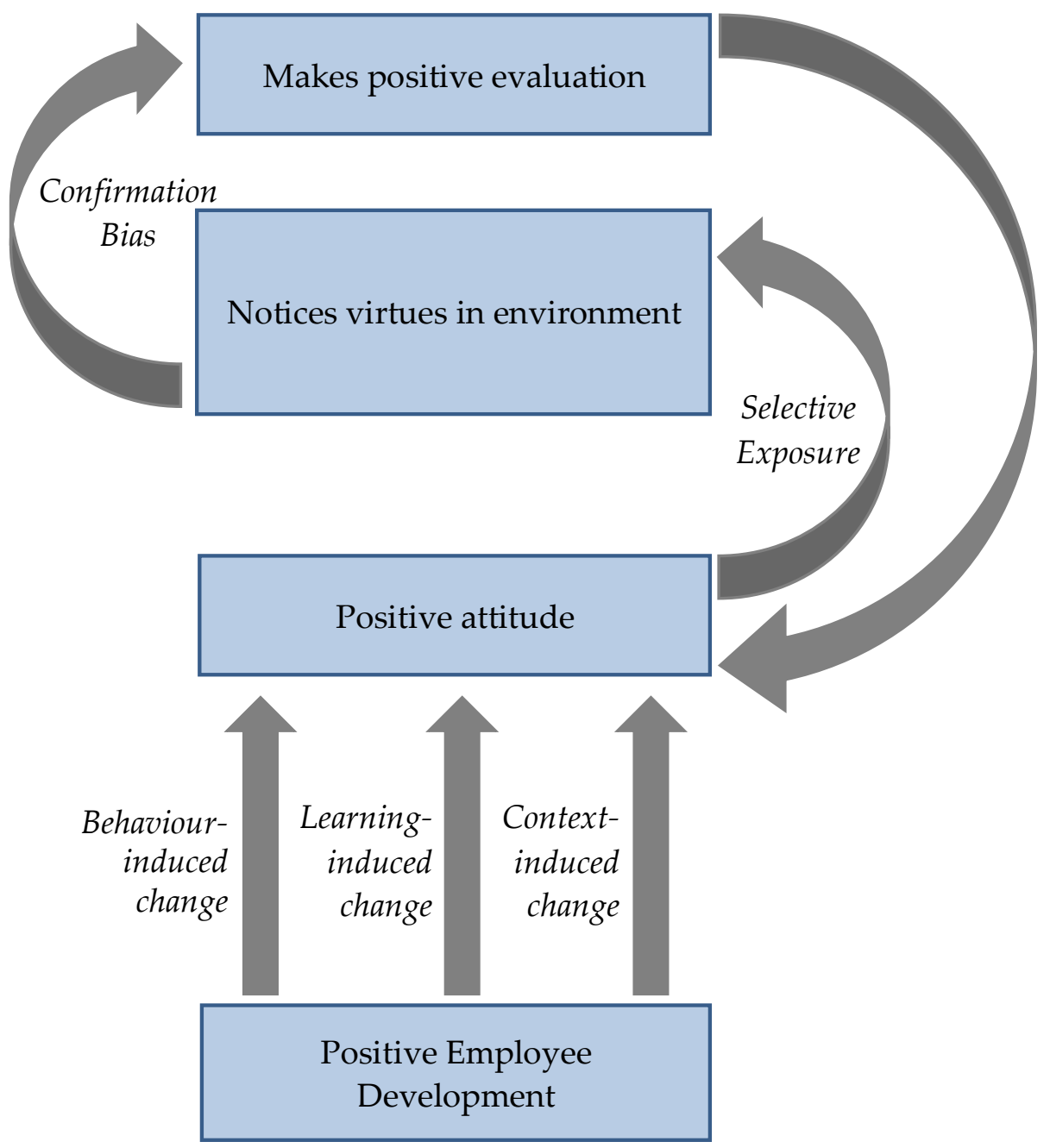

Returning to the example of the new manager, the team members focused on the positive behaviors (selective exposure), which confirmed their desire for positive change (confirmation bias). By consistently implementing virtuous behaviors, the manager further develops the team members' positive attitudes through learning and context change; consequently, team members 
are more likely to attend to positive aspects in the environment and behave in ways that are attitude congruent, thus contributing to the positive environment. This creates a positive energy feedback loop in which the virtues-based organization environment and increasingly positive individual attitudes are mutually supportive and reinforcing over time.

\subsubsection{Connecting the pieces}

Coming full circle, the complete IO-OI model (Figure 2) details the six propositions proposed in this paper. The model depicts the interrelationships between the inside-out approach of developing individual resources through positive attitudes, and the outside-in approach of developing social resources through virtuous organizational culture. Early evidence suggests that both approaches enable and support the development of work happiness independently and synergistically (Williams, Kern, \& Waters, 2015).

Figure 2 also shows a number of feedback loops that create and sustain upward spirals of positive development and support the IO-OI model as a self-sustaining positive energy system. The development of higher levels of work happiness is experienced as greater satisfaction, commitment, and engagement of members, thus increasing their awareness and receptivity to positive practices (feedback loop (a)), their enactment of congruent behaviors that support a virtuous culture (feedback loop (b)), their motivation to engage in positive development (feedback loop (c)), and positive attitudes such as PsyCap (feedback loop (d)). Thus the process of developing work happiness can be an iterative cycle that unfolds in a dynamic fashion over time and is mutually affected by inside-out and outside-in influences and feedback loops.

The IO-OI model suggests an iterative process for developing positive attitudes within individuals, but how does this benefit an organization? We suggest that by increasing positive attitudes in many members, collective change may occur. When a critical mass is reached, there is greater capacity for virtuousness across the whole system. The IO-OI model suggests that this may arise in a number of ways. First, as people develop positive attitudes such as hope, optimism, resilience, and efficacy, they will be more open to seeing virtuousness in the organization culture because it is attitude congruent. As such, through the processes of selective exposure and confirmation bias, they perceive more virtuousness in others and evaluate other people's behaviors from a virtues perspective. Haidt's (2000) elevation proposition suggests that when we perceive virtuous behavior in others, we are motivated/elevated to behave virtuously ourselves. Hence, by seeing more virtues in others, organization members may behave more virtuously themselves. Second, Fowler and Christakis' (2008) contagion theory suggests that emotions and behaviors are spread through social networks. As employee positive attitudes are manifest through positive thoughts, feelings, and behaviors, they may positively influence colleagues to feel and behave in a similar way.

\section{Future research: testing the model}

We have suggested a theoretical model that links inside-out and outside-in factors, with a series of six propositions. These need to be empirically tested. A number of fruitful research questions can be addressed using the IO-OI model. For instance: 1) How are inside-out and outside-in interventions most effectively introduced - all at once or over time to allow integration into attitudes? 2) Are there factors about the existing culture that influence the success of the IO-OI model (e.g., a constructive culture orientation versus a destructive culture orientation)? 3) How might the cultural context influence the processes described in the model? 4) Are there certain types of leaders who are best to lead the IO-OI development process? Should organizations which want to develop work happiness and a virtuous culture recruit people with high PsyCap? 
The answers to these questions will help to inform organizations of the best approach to follow when developing employee work happiness using a dual intervention approach.

Multiple approaches can be used to test the model and propositions. It would be of interest to understand how differences in taking an outside-in (positive practices and virtuous culture) or inside-out (positive employee development and positive attitudes) approach impacts work happiness, and how different phasing and timing of these two approaches affects employee wellbeing outcomes. Organizations with multiple departments or business units within the same parent culture would provide a valuable setting to undertake such comparative tests, with one unit using an inside-out and the other using an outside-in approach. It would also be beneficial to test the IO-OI model within a variety of organizational contexts (e.g., a not-for-profit organization such as a school and a profit-driven industry such as a merchant bank).

Longitudinal studies of the IO-OI model may help to uncover the potential time-lag between implementing specific interventions and changes in levels of work happiness. For example, Cameron et al. (2011) assessed the extent to which positive practices affected organization performance over time and which practices had the most predictive power across 29 nursing units. Longitudinal designs also provide a time-perspective to the reciprocal loop between the development of positive attitudes and positive practices, which will help organizations understand the frequency with which they need to positively trigger employees' re-evaluative cycle through the workplace environment to sustain employee wellbeing.

Attitudes can be challenging to measure, but these inherent challenges can be overcome through creative and varied approaches to measurement. Use of everyday experience methods such as the daily diary (Bolger, Davis, \& Rafaeli, 2003) and experience sampling method (ESM, Hektner, Schmidt, \& Cziksentmihayli, 2007) will help minimize retrospection bias (Reis, Gable, \& Mancini, 2014), and will allow researchers to test the IO-OI model through everyday behaviors that occur in the natural workplace setting. The data from such methods will provide a valuable detailed picture of employees' experience of the work environment, their attitudes at work, and the individual and context factors that influence them (Tennen, Suls, \& Affleck, 1991). Interpretation-based measures of attitudes such as sentence completion tasks and projective vignettes may be useful to access less conscious, implicit attitudes. These measures are effective in assessing complex social beliefs (such as perception of virtues) and motivational constructs (such as work happiness - engagement, satisfaction and commitment) (Uhlmann et al., 2012) that are part of the IO-OI model.

Organizations can collect meaningful performance outcomes for the department/unit/organization as a way to assess the usefulness of adopting the IO-OI model. Studies have shown that performance indicators such as employee turnover, organizational climate, financial performance, sales performance, client/customer satisfaction, psychological wellbeing, group performance, organizational citizenship behaviors and trust, are influenced by constructs within the IO-OI model and are of interest to organizations wanting to improve their effectiveness and performance (Avey, Luthans, Smith, \& Palmer, 2010; Avey, Wernsing, \& Luthans, 2008; Cameron et al., 2011; Youssef \& Luthans, 2007). These measures could be taken prior to and after the interventions (e.g., training, mentoring, the use of specific positive practices) and could be analyzed via panel data analysis and latent growth modeling.

\section{Conclusion}

Gavin and Mason (2004) argue that "to achieve the good life people must work in good organizations" (p. 387). The current paper has suggested that a dual approach involving both outside-in interventions and inside-out interventions may be most effective in creating positive 
institutions and flourishing individuals within them. Adopting a positive systems science perspective, the IO-OI model outlines the interrelationships and processes through which insideout and outside-in factors positively influence employee work happiness, and suggests three processes that may explain the interaction between outside-in and inside-out approaches. Further, the model proposes a number of feedback loops that enable upward spirals of positive development at the individual and organizational level, and support the model as a selfsustaining positive energy system embedded in a workplace context.

The IO-OI model integrates the fields of attitudes, positive organizational scholarship, and positive organizational behavior. Further, the model explains one way in which individual personal resources such as positive affect and core-self-evaluation interact with organizational job and social resources such as colleague support and supervisor feedback to create pathways for organizations to develop and sustain the wellbeing of its members. As such, the IO-OI model addresses the current imbalance in positive psychology that has focused more individual positive psychology interventions than a whole-of-system approach and on individual wellbeing applications than on workplace interventions. We hope that through the IO-OI model, workplace practitioners can further understand the importance of adopting both inside-out and outside-in approaches when fostering employee work happiness.

\section{Authors}

Paige Williams

The University of Melbourne

paige.williams@unimelb.edu.au

Margaret L. Kern

The University of Melbourne

Lea Waters

The University of Melbourne

\section{Publishing Timeline}

Received 14 December 2015

Accepted 21 June 2016

Published 14 September 2016

\section{References}

Ajzen, I. (2001). Nature and operation of attitudes. Annual Review of Psychology, 52, 27-58. http://dx.doi.org/10.1146/annurev.psych.52.1.27

Avey, J. B., Luthans, F., Smith, R. M., \& Palmer, N. F. (2010). Impact of positive psychological capital on employee well-being over time. Journal of Occupational Health Psychology, 15(1), 17-28. http://dx.doi.org/10.1037/a0016998

Avey, J. B., Wernsing, T. S., \& Luthans, F. (2008). Can positive employees help positive organizational change? Impact of psychological capital and emotions on relevant attitudes and behaviors. The Journal of Applied Behavioral Science, 44(1), 48-70. http://dx.doi.org/10.1177/0021886307311470

Baeyens, F., Eelen, P., Crombez, G., \& Van den Bergh, O. (1992). Human evaluative conditioning: Acquisition trials, presentation schedule, evaluative style and contingency awareness. Behaviour research and therapy, 30(2), 133-142. http://dx.doi.org/10.1016/0005-7967(92)90136-5

Bakker, A. B., \& Demerouti, E. (2008). Towards a model of work engagement. Career Development International, 13(3), 209-223. http://dx.doi.org/10.1108/13620430810870476 
Barends, E., Janssen, B., ten Have, W., \& ten Have, S. (2013). Effects of change interventions: What kind of evidence do we really have? The Journal of Applied Behavioral Science, 50(1), 5-27. http://dx.doi.org/10.1177/0021886312473152

Bartlett, C. A., \& Ghoshal, S. (2002). Building competitive advantage through people. MIT Sloan Management Review, 43(2), 34-41.

Bartlett, C. A., \& Ghoshal, S. (2002). New organizational responses. Strategy: Critical Perspectives on Business and Management, 3(1), 468.

Bem, D. J. (1967). Self-perception: An alternative interpretation of cognitive dissonance phenomena. Psychological Review, 74(3), 183-200. http://dx.doi.org/10.1037/h0024835

Blascovich, J., Ernst, J. M., Tomaka, J., Kelsey, R. M., Salomon, K. L., \& Fazio, R. H. (1993). Attitude accessibility as a moderator of autonomic reactivity during decision making. Journal of Personality and Social Psychology, 64(2), 165-176. http://dx.doi.org/10.1037/0022-3514.64.2.165

Bodenhausen, G. V., \& Gawronski, B. (2013). Attitude change. In D. Reisberg (Ed.), The Oxford handbook of cognitive psychology (pp. 957-969). New York, NY: Oxford University Press. http://dx.doi.org/10.4135/9781452257044.n29

Boehm, J. K., \& Lyubomirsky, S. (2008). Does happiness promote career success? Journal of Career Assessment, 16(1), 101-116. http://dx.doi.org/10.1177/1069072707308140

Bohner, G., \& Dickel, N. (2011). Attitudes and attitude change. Annual Review of Psychology, 62, 391-417. http://dx.doi.org/10.1146/annurev.psych.121208.131609

Bolger, N., Davis, A., \& Rafaeli, E. (2003). Diary methods: Capturing life as it is lived. Annual Review of Psychology, 54(1), 579-616. http://dx.doi.org/10.1146/annurev.psych.54.101601.145030

Bouskila-Yam, O., \& Kluger, A. N. (2011). Strength-based performance appraisal and goal setting. Human Resource Management Review, 21(2), 137-147. http://dx.doi.org/10.1016/j.hrmr.2010.09.001

Burnes, B. (1996). No such thing as... a "one best way" to manage organizational change. Management Decision, 34(10), 11-18. http://dx.doi.org/10.1108/00251749610150649

Burnes, B. (2004). Kurt Lewin and the planned approach to change: A re-appraisal. Journal of Management Studies, 41(6), 977-1002. http://dx.doi.org/10.1111/j.1467-6486.2004.00463.x

Butler, J., \& Kern, M. L. (2015). The PERMA-Profiler: A brief multidimensional measure of flourishing. http://www.peggykern.org/questionnaires.html

Cameron, K. (2008). A process for changing organization culture. Handbook of Organization Development, $14(5), 2-18$.

Cameron, K. (2013). Practicing positive leadership: Tools and techniques that create extraordinary results: San Francisco, CA: Berrett-Koehler.

.Cameron, K. S., Bright, D., \& Caza, A. (2004). Exploring the relationships between organizational virtuousness and performance. American Behavioral Scientist, 47(6), 766-790.

http://dx.doi.org/10.1177/0002764203260209

Cameron, K. S., Dutton, J. E., \& Quinn, R. E. (2003). Positive organizational scholarship: Foundations of a new discipline. San Francisco, CA: Berrett-Koehler.

Cameron, K., \& Caza, A. (2002). Organizational and leadership virtues and the role of forgiveness. Journal of Leadership \& Organizational Studies, 9(1), 33-48. http://dx.doi.org/10.1177/107179190200900103

Cameron, K., Mora, C., Leutscher, T., \& Calarco, M. (2011). Effects of positive practices on organizational effectiveness. The Journal of Applied Behavioral Science, 47(3), 266-308. http://dx.doi.org/10.1177/0021886310395514

Cameron, K., \& Plews, E. (2012). Positive leadership in action: Applications of POS by Jim Mallozzi, CEO, Prudential Real Estate and Relocation. Organizational Dynamics, 41(2), 99-105. http://dx.doi.org/10.1016/j.orgdyn.2012.01.003

Cameron, K. S., \& Spreitzer, G. M. (2011). The Oxford handbook of positive organizational scholarship. New York, NY: Oxford University Press.

Cameron, K., \& Winn, B. (2012). Virtuousness in organizations. In K. S. Cameron\& G. M. Spreitzer (Eds.), The Oxford handbook of positive organizational scholarship (pp. 231-243). New York, NY: Oxford University Press. 
Chang, K., \& Lu, L. (2007). Characteristics of organizational culture, stressors and wellbeing. Journal of Managerial Psychology, 22(6), 549-568. http://dx.doi.org/10.1108/02683940710778431

Cooke, R. A., \& Rousseau, D. M. (1988). Behavioral norms and expectations: A quantitative approach to the assessment of organizational culture. Group \& Organization Management, 13(3), 245-273. http://dx.doi.org/10.1177/105960118801300302

Cotton, P., \& Hart, P. M. (2003). Occupational wellbeing and performance: A review of organisational health research. Australian Psychologist, 38(2), 118-127. http://dx.doi.org/10.1080/00050060310001707117

Cunningham, W. A., \& Zelazo, P. D. (2007). Attitudes and evaluations: A social cognitive neuroscience perspective. Trends in Cognitive Sciences, 11(3), 97-104. http://dx.doi.org/10.1016/j.tics.2006.12.005

Diener, E., Emmons, R. A., Larsen, R. J., \& Griffin, S. (1985). The satisfaction with life scale. Journal of Personality Assessment, 49(1), 71-75. http://dx.doi.org/10.1207/s15327752jpa4901 13

Diener, E., Sandvik, E., \& Pavot, W. (1991). Happiness is the frequency, not the intensity, of positive versus negative affect. Subjective Well-being: An Interdisciplinary Perspective, 21, 119-139.

Diener, E., Suh, E. M., Lucas, R. E., \& Smith, H. L. (1999). Subjective well-being: Three decades of progress. Psychological Bulletin, 125, 276-302. http://dx.doi.org/10.1037/0033-2909.125.2.276

Diener, E., Wirtz, D., Tov, W., Kim-Prieto, C., Choi, D.-W., Oishi, S., \& Biswas-Diener, R. (2010). New well-being measures: Short scales to assess flourishing and positive and negative feelings. Social Indicators Research, 97(2), 143-156. http://dx.doi.org/10.1007/s11205-009-9493-y

Doherty, M. E., \& Mynatt, C. R. (1986). The magical number one. In D. Moates \& R. Butrick (Eds.), Inference OUIC 86. Proceedings of the Ohio University Interdisciplinary Conference on Inference 86 (pp. 221-230). Athens, OH: Ohio University.

Donaldson, S. I., Dollwet, M., \& Rao, M. A. (2014). Happiness, excellence, and optimal human functioning revisited: Examining the peer-reviewed literature linked to positive psychology. The Journal of Positive Psychology, 10(3), 185-195. http://dx.doi.org/10.1080/17439760.2014.943801

Dunphy, D., \& Stace, D. (1993). The strategic management of corporate change. Human Relations, 46(8), 905-920. http://dx.doi.org/10.1177/001872679304600801

Eagly, A. H., \& Chaiken, S. (1993). The psychology of attitudes. Orlando, FL: Harcourt Brace Jovanovich College.

Faragher, E. B., Cass, M., \& Cooper, C. L. (2005). The relationship between job satisfaction and health: A meta-analysis. Occupational and Environmental Medicine, 62(2), 105-112. http://dx.doi.org/10.1136/oem.2002.006734

Fazio, R. H. (1990). The MODE model as an integrative framework. Advances in Experimental Social Psychology, 23, 75-109. http://dx.doi.org/10.1016/S0065-2601(08)60318-4

Fazio, R. H. (2000). Accessible attitudes as tools for object appraisal: Their costs and benefits. In G. R. Maio \& J. M. Olson (Eds.), Why we evaluate: Functions of attitudes (pp. 1-36). Mahwah, NJ: Lawrence Erlbaum Associates

Fazio, R. H., Blascovich, J., \& Driscoll, D. M. (1992). On the functional value of attitudes: The influence of accessible attitudes on the ease and quality of decision making. Personality and Social Psychology Bulletin, 18(4), 388-401. http://dx.doi.org/10.1177/0146167292184002

Fazio, R. H., \& Olson, M. A. (2007). Attitudes: Foundations, functions, and consequences. In J. C. M. A. Hogg (Ed.), The handbook of social psychology (pp. 123-145). London: Sage. http://dx.doi.org/10.4135/9781848608221.n6

Festinger, L. (1962). A theory of cognitive dissonance (Vol. 2). Stanford, CA. Stanford University Press.

Fischer, P., Fischer, J., Weisweiler, S., \& Frey, D. (2010). Selective exposure to information: How different modes of decision making affect subsequent confirmatory information processing. British Journal of Social Psychology, 49(4), 871-881. http://dx.doi.org/10.1348/014466610X499668

Fishbein, M., \& Ajzen, I. (1975). Belief, attitude, intention and behavior: An introduction to theory and research. Reading, MA: Addison-Wesley.

Fisher, C. D. (2010). Happiness at work. International Journal of Management Reviews, 12(4), 384-412. http://dx.doi.org/10.1111/j.1468-2370.2009.00270.x 
Fisher, C. D., \& Boyle, G. J. (1997). Personality and employee selection: Credibility regained. (School of Business Discussion Paper No. 62). http://epublications.bond.edu.au/discussion_papers/62

Fowler, J. H., \& Christakis, N. A. (2008). Dynamic spread of happiness in a large social network: Longitudinal analysis over 20 years in the Framingham Heart Study. British Medical Journal, 337(a2338), 1-9. http://dx.doi.org/10.1136/bmj.a2338

Gable, S. L., \& Haidt, J. (2005). What (and why) is positive psychology? Review of General Psychology, 9(2), 103-110. http://dx.doi.org/10.1037/1089-2680.9.2.103

Gavin, J. H., \& Mason, R. O. (2004). The virtuous organization: The value of happiness in the workplace. Organizational Dynamics, 33(4), 379-392. http://dx.doi.org/10.1016/j.orgdyn.2004.09.005

Giardini, A., \& Frese, M. (2008). Linking service employees' emotional competence to customer satisfaction: A multilevel approach. Journal of Organizational Behavior, 29(2), 155-170. http://dx.doi.org/10.1002/job.509

Gorgievski, M. J., Bakker, A. B., \& Schaufeli, W. B. (2010). Work engagement and workaholism: Comparing the self-employed and salaried employees. The Journal of Positive Psychology, 5(1), 83-96. http://dx.doi.org/10.1080/17439760903509606

Haidt, J., Algoe, S., Meijer, Z., Tam, A., \& Chandler, E. C. (2000). The elevation-altruism proposition: Evidence for a new prosocial emotion. (Unpublished manuscript). University of Virginia, Charlottesville, VA.

Harms, P. D., \& Luthans, F. (2012). Measuring implicit psychological constructs in organizational behavior: An example using psychological capital. Journal of Organizational Behavior, 33(4), 589-594. http://dx.doi.org/10.1002/job.1785

Hartel, C. E. J., Ashkanasy, N. M. (2011). Healthy human cultures as positive work environments, (2nd ed.). Thousand Oaks, CA, USA: Sage. http://dx.doi.org/10.4135/9781483307961.n6

Harter, J. K., Schmidt, F. L., \&and Keyes, C. L. (2003). Well-being in the workplace and its relationship to business outcomes: A review of the Gallup studies. Flourishing: Positive Psychology and the Life Welllived, 2, 205-224. http://dx.doi.org/10.1037/10594-009

Heider, F. (1958). The psychology of interpersonal relations. New York, NY: Wiley. http://dx.doi.org/10.1037/10628-000

Hektner, J. M., Schmidt, J. A., \& Csikszentmihalyi, M. (2007). Experience sampling method: Measuring the quality of everyday life. Thousand Oaks, CA: Sage. http://dx.doi.org/10.4135/9781412984201

Hergovich, A., Schott, R., \& Burger, C. (2010). Biased evaluation of abstracts depending on topic and conclusion: Further evidence of a confirmation bias within scientific psychology. Current Psychology, 29(3), 188-209. http://dx.doi.org/10.1007/s12144-010-9087-5

Hildum, D. C., \& Brown, R. W. (1956). Verbal reinforcement and interviewer bias. The Journal of Abnormal and Social Psychology, 53(1), 108-111. http://dx.doi.org/10.1037/h0040518

Hobfoll, S. E., Johnson, R. J., Ennis, N., \& Jackson, A. P. (2003). Resource loss, resource gain, and emotional outcomes among inner city women. Journal of Personality and Social Psychology, 84(3), 632643. http://dx.doi.org/10.1037/0022-3514.84.3.632

Hone, L. C., Jarden, A., Schofield, G., \& Duncan, S. (2014). Measuring flourishing: The impact of operational definitions on the prevalence of high levels of wellbeing. International Journal of Wellbeing, 4(1), 62-90. http://dx.doi.org/10.5502/ijw.v4i1.4

Huppert, F. A., \& So, T. T. (2013). Flourishing across Europe: Application of a new conceptual framework for defining well-being. Social Indicators Research, 110(3), 837-861. http://dx.doi.org/10.1007/s11205011-9966-7

Jomini Stroud, N. J. (2007). Media effects, selective exposure, and Fahrenheit 9/11. Political Communication, 24(4), 415-432. http://dx.doi.org/10.1080/10584600701641565

Judge, T. A., \& Kammeyer-Mueller, J. D. (2012). Job attitudes. Annual Review of Psychology, 63(1), 341-367. http://dx.doi.org/10.1146/annurev-psych-120710-100511

Judge, T. A., Thoresen, C. J., Bono, J. E., \& Patton, G. K. (2001). The job satisfaction-job performance relationship: A qualitative and quantitative review. Psychological Bulletin, 127(3), 376-407.

http://dx.doi.org/10.1037/0033-2909.127.3.376 
Kashdan, T. B., Biswas-Diener, R., \& King, L. A. (2008). Reconsidering happiness: The costs of distinguishing between hedonics and eudaimonia. The Journal of Positive Psychology, 3(4), $219-233$. http://dx.doi.org/10.1080/17439760802303044

Kastenmüller, A., Greitemeyer, T., Jonas, E., Fischer, P., \& Frey, D. (2010). Selective exposure: The impact of collectivism and individualism. British Journal of Social Psychology, 49(4), 745-763. http://dx.doi.org/10.1348/014466609X478988

Katz, D. (1960). The functional approach to the study of attitudes. Public Opinion Quarterly, 24 (2), $163-$ 204. http://dx.doi.org/10.1086/266945

Kern, M. L., Siokou, C., Oades, L. G., \& Spong, C. (2016, June). Positive System Science. Poster session presented at the 8th European Conference on Positive Psychology, Angers, France.

Kesebir, P., \& Diener, E. (2008). In pursuit of happiness: Empirical answers to philosophical questions. Perspectives on Psychological Science, 3(2), 117-125. http://dx.doi.org/10.1111/j.1745-6916.2008.00069.x

Keyes, C. L. (2002). The mental health continuum: From languishing to flourishing in life. Journal of Health and Social Behavior, 43(2), 207-222. http://dx.doi.org/10.2307/3090197

Keyes, C. L. (2005). Mental illness and/or mental health? Investigating axioms of the complete state model of health. Journal of Consulting and Clinical Psychology, 73(3), 539-548. http://dx.doi.org/10.1037/0022-006X.73.3.539

Keyes, C. L., \& Annas, J. (2009). Feeling good and functioning well: Distinctive concepts in ancient philosophy and contemporary science. The Journal of Positive Psychology, 4(3), 197-201. http://dx.doi.org/10.1080/17439760902844228

Klapper, J. T. (1960). The effects of mass communication. Glencoe: The Free Press.

Kristjánsson, K. (2012). Positive psychology and positive education: Old wine in new bottles? Educational Psychologist, 47(2), 86-105. http://dx.doi.org/10.1080/00461520.2011.610678

LePine, J. A., Erez, A., \& Johnson, D. E. (2002). The nature and dimensionality of organizational citizenship behavior: A critical review and meta-analysis. Journal of Applied Psychology, 87(1), 52-65. http://dx.doi.org/10.1037//0021-9010.87.1.52

Lewin, K. (1946). Action research and minority problems. Journal of Social Iissues, 2(4), 34-46. http://dx.doi.org/10.1111/j.1540-4560.1946.tb02295.x

Linley, A. P., Joseph, S., Harrington, S., \& Wood, A. M. (2006). Positive psychology: Past, present, and (possible) future. The Journal of Positive Psychology, 1(1), 3-16. http://dx.doi.org/10.1080/17439760500372796

Locke, E. A. (1976). The nature and causes of job satisfaction. In M. D. Dunnette (Ed.), Handbook of industrial E organizational psychology (pp. 1297-1343). Chicago, IL: Rand-McNally.

Lorange, P. (2005). Strategy means choice: Also for today's business school! Journal of Management Development, 24(9), 783-790. http://dx.doi.org/10.1108/02621710510621295

Luthans, F., Avey, J. B., \& Patera, J. L. (2008). Experimental analysis of a web-based training intervention to develop positive psychological capital. Academy of Management Learning E Education, 7(2), 209-221. http://dx.doi.org/10.5465/AMLE.2008.32712618

Luthans, F., Avey, J. B., Avolio, B. J., \& Peterson, S. J. (2010). The development and resulting performance impact of positive psychological capital. Human Resource Development Quarterly, 21(1), 41-67. http://dx.doi.org/10.1002/hrdq.20034

Luthans, F., Avolio, B. J., \& Avey, J. B. (2007). Psychological capital questionnaire. http://www.mindgarden.com

Luthans, F., Avolio, B. J., Avey, J. B., \& Norman, S. M. (2007). Positive psychological capital: Measurement and relationship with performance and satisfaction. Personnel Psychology, 60(3), 541572. http://dx.doi.org/10.1111/j.1744-6570.2007.00083.x

Luthans, F., \& Church, A. H. (2002). Positive organizational behavior: Developing and managing psychological strengths [and Executive Commentary]. The Academy of Management Executive (19932005), 16(1), 57-75.

Luthans, F., Norman, S. M., Avolio, B. J., \& Avey, J. B. (2008). The mediating role of psychological capital in the supportive organizational climate-employee performance relationship. Journal of Organizational Behavior, 29(2), 219-238. http://dx.doi.org/10.1002/job.507 
Luthans, F., Youssef, C. M., \& Avolio, B. J. (2006). Psychological capital: Developing the human competitive edge: Oxford, United Kingdom: Oxford University Press. http://dx.doi.org/10.1093/acprof:oso/9780195187526.001.0001

Lyubomirsky, S. (2007). The how of happiness: A new approach to getting the life you want. New York, NY: Penguin Press.

Lyubomirsky, S., \& Layous, K. (2013). How do simple positive activities increase well-being? Current Directions in Psychological Science, 22(1), 57-62. http://dx.doi.org/10.1177/0963721412469809

Martin, G., Beaumont, P., Doig, R., \& Pate, J. (2005). Branding: A new performance discourse for HR? European Management Journal, 23(1), 76-88. http://dx.doi.org/10.1016/j.emj.2004.12.011

Masten, A. S., \& Reed, M. G. J. (2002). Resilience in development. In C. R. Snyder \& S. J. Lopez (Eds.), Handbook of positive psychology (pp. 74-88). Oxford, United Kingdom: Oxford University Press.

Matlin, M. W., \& Stang, D. J. (1978). The Pollyanna principle: Selectivity in language, memory, and thought. Cambridge, MA: Schenkman.

Meyer, J. P., \& Allen, N. J. (1984). Testing the "side-bet theory" of organizational commitment: Some methodological considerations. Journal of Applied Psychology, 69(3), 372-378. http://dx.doi.org/10.1037/0021-9010.69.3.372

Meyer, J. P., Stanley, D. J., Herscovitch, L., \& Topolnytsky, L. (2002). Affective, continuance, and normative commitment to the organization: A meta-analysis of antecedents, correlates, and consequences. Journal of Vocational Behavior, 61(1), 20-52. http://dx.doi.org/10.1006/jvbe.2001.1842

Mobley, W. H. (1977). Intermediate linkages in the relationship between job satisfaction and employee turnover. Journal of Applied Psychology, 62(2), 237-240. http://dx.doi.org/10.1037/0021-9010.62.2.237

Mowday, R. T., Steers, R. M., \& Porter, L. W. (1979). The measurement of organisational commitment. Journal of Vocational Behavior, 14, 224-247. http://dx.doi.org/10.1016/0001-8791(79)90072-1

Nickerson, R. S., (1998). Confirmation bias: A ubiquitous phenomenon in many guises. Review of General Psychology, 2 (2), 175-220. http://dx.doi.org/10.1037/1089-2680.2.2.175

Page, K. (2005). Subjective wellbeing in the workplace. Geelong, Australia: Deakin University.

Page, K., \& Vella-Brodrick, D. (2009). The 'what', 'why' and 'how' of employee well-being: A new model. Social Indicators Research, 90(3), 441-458. http://dx.doi.org/10.1007/s11205-008-9270-3

Parker, J. (2001). Where layoffs are a last resort: Treating them as unthinkable can have big benefits. http://www.bloomberg.com/bw/stories/2001-10-07/where-layoffs-are-a-last-resort

Pavlov, I. P. (1927/1960). Conditioned reflexes: An investigation of the physiological activity of the cerebral cortex. London, United Kingdom: Oxford University Press.

Pennington, N., \& Hastie, R. (1993). Reasoning in explanation-based decision making. Cognition, 49(1), 123-163. http://dx.doi.org/10.1016/0010-0277(93)90038-W

Peterson, C. S., \& Seligman, M. E. P. (2004). Character strengths and virtues: A handbook and classification. Washington, D.C: American Psychological Association.

Peterson, C. S., M.E.P. (2004). Character Strengths and Virtues: A Handbook and Classification. Washington D.C.: American Psychological Association.

PricewaterhouseCoopers. (2014). Workplace wellness in Australia. http://www.usc.edu.au/media/3121/WorkplaceWellnessinAustralia.pdf

Reis, H. T., Gable, S. L., \& Maniaci, M. R. (2014). Methods for studying everyday experience in its natural context. In H. T. J. Reis \& C. M. Judd (Eds.), Handbook of research methods in social and personality psychology (2nd ed.) (pp. 373-404). New York, NY: Cambridge University Press.

Reis, H. T., Gable, S. L., \& Maniaci, M. R. (2014). Methods for studying everyday experience in its natural context. In H. T. Reis \& C. M. Judd (Eds), Handbook of research methods in social and personality psychology (2nd ed.) (pp. 373-403). New York: Cambridge University Press.

Richard, E., \& Diener, E. (2009). Personality and subjective well-being. In E. Diener (Ed.), The science of well-being (Vol. 57, pp. 75-102). Dordrecht, The Netherlands: Springer.

Rosenberg, M. J., \& Hovland, C. I. (1960). Cognitive, affective, and behavioral components of attitudes. In M. J. Rosenberg \& C. I. Hovland (Eds.), Attitude organization and change: An analysis of consistency among attitude components, 3, 1-14. New Haven, CT: Yale University Press. 
Rothbard, N. P., \& Patil, S. V. (2012). Being there: Work engagement and positive organizational scholarship. In K. S. Cameron \& G. M. Spreitzer (Eds.), The Oxford handbook of positive organizational scholarship (pp. 56-68). New York, NY: Oxford University Press.

Rusk, R., \& Waters, L. (2013). Tracing the size, reach, impact and breadth of positive psychology. Journal of Positive Psychology, 8(3), 207-221. http://dx.doi.org/10.1080/17439760.2013.777766

Ryan, R. M., \& Deci, E. L. (2001). On happiness and human potentials: A review of research on hedonic and eudaimonic well-being. Annual Review of Psychology, 52(1), 141-166.

http://dx.doi.org/10.1146/annurev.psych.52.1.141

Ryff, C. D., \& Singer, B. H. (2008). Know thyself and become what you are: A eudaimonic approach to psychological well-being. Journal of Happiness Studies, 9(1), 13-39. http://dx.doi.org/10.1007/s10902006-9019-0

Saari, L. M., \& Judge, T. A. (2004). Employee attitudes and job satisfaction. Human Resource Management, 43(4), 395-407. http://dx.doi.org/10.1002/hrm.20032

Schaufeli, W., \& Bakkar, A. (2003). Utrecht work engagement scale preliminary manual. Utrecht, The Netherlands: Occupational Health Psychology Unit, Utrecht University.

Scheier, M. F., \& Carver, C. S. (1985). Optimism, coping, and health: Assessment and implications of generalized outcome expectancies. Health Psychology, 4(3), 219-247. http://dx.doi.org/10.1037/02786133.4.3.219

Schein, E. H. (1980). Organizational psychology. 1980. Englewood Cliffs, NJ: Reprinted by permission of Prentice-Hall., Inc., Englewood Cliffs, NJ, 177-178.

Schimmack, U. (2008). The structure of subjective well-being. In M. Eid \& R. Larsen (Eds.), The science of subjective well-being (pp. 97-123). New York, NY: Guildford Press.

Sears, L. E., Shi, Y., Coberley, C. R., \& Pope, J. E. (2013). Overall well-being as a predictor of health care, productivity, and retention outcomes in a large employer. Population Health Management, 16(6), 397405. http://dx.doi.org/10.1089/pop.2012.0114

Seligman, M. E. (2012). Flourish: A visionary new understanding of happiness and well-being. New York, NY: Simon and Schuster.

Seligman, M., \& Csikszentmihalyi, M. (2000). Positive psychology: An introduction. American Psychologist, 55, 5-14. http://dx.doi.org/10.1037/0003-066X.55.1.5

Sloan, R. P. (1987). Workplace health promotion: A commentary on the evolution of a paradigm. Health Education \& Behavior, 14(2), 181-194. http://dx.doi.org/10.1177/109019818701400205

Sloan, R. P., \& Gruman, J. C. (1988). Participation in workplace health promotion programs: The contribution of health and organizational factors. Health Education \& Behavior, 15(3), 269-288. http://dx.doi.org/10.1177/109019818801500303

Smith, E. R., Fazio, R. H., \& Cejka, M. A. (1996). Accessible attitudes influence categorization of multiply categorizable objects. Journal of Personality and Social Psychology, 71(5), 888-898.

http://dx.doi.org/10.1037/0022-3514.71.5.888

Snyder, C. R., Harris, C., Anderson, J. R., Hollaran, S. A., Irving, L. M., Sigmon, S. T., . . \& Harney, P. (1991). The will and the ways: development and validation of an individual-differences measure of hope. Journal of Personality and Social Psychology, 60(4), 570-585. http://dx.doi.org/10.1037/00223514.60.4.570

Spreitzer, G. M., \& Sonenshein, S. (2004). Toward the construct definition of positive deviance. American Behavioral Scientist, 47(6), 828-847. http://dx.doi.org/10.1177/0002764203260212

Stajkovic, A. D., \& Luthans, F. (1998). Self-efficacy and work-related performance: A meta-analysis. Psychological Bulletin, 124(2), 240-261. http://dx.doi.org/10.1037/0033-2909.124.2.240

Stroud, N. J. (2007). Media effects, selective exposure, and Fahrenheit 9/11. Political Communication, 24(4), 415-432. http://dx.doi.org/10.1080/10584600701641565

Tennen, H., Suls, J., \& Affleck, G. (1991). Personality and daily experience: The promise and the challenge. Journal of Personality, 59(3), 313-337. http://dx.doi.org/10.1111/j.1467-6494.1991.tb02387.x

Todnem By, R. (2005). Organisational change management: A critical review. Journal of Change Management, 5(4), 369-380. http://dx.doi.org/10.1080/14697010500359250 
Tourangeau, R., \& Rasinski, K. A. (1988). Cognitive processes underlying context effects in attitude measurement. Psychological Bulletin, 103(3), 299-314. http://dx.doi.org/10.1037/0033-2909.103.3.299

Tuchkman, B. W. (1984). The march of folly: From Troy to Vietnam. New York, NY: Random House.

Uhlmann, E. L., Leavitt, K., Menges, J. I., Koopman, J., Howe, M., \& Johnson, R. E. (2012). Getting explicit about the implicit: A taxonomy of implicit measures and guide for their use in organizational research. Organizational Research Methods, 15(4), 553-601. http://dx.doi.org/10.1177/1094428112442750

Van Bavel, J. J., Xiao, Y. J., \& Cunningham, W. A. (2012). Evaluation is a dynamic process: Moving beyond dual system models. Social and Personality Psychology Compass, 6(6), 438-454. http://dx.doi.org/10.1111/j.1751-9004.2012.00438.x

Van De Voorde, K., Paauwe, J., \& Van Veldhoven, M. (2012). Employee well-being and the HRMorganizational performance relationship: A review of quantitative studies. International Journal of Management Reviews, 14(4), 391-407. http://dx.doi.org/10.1111/j.1468-2370.2011.00322.x

Waters, L. (2011). A review of school-based positive psychology interventions. The Australian Educational and Developmental Psychologist, 28(2), 75-90. http://dx.doi.org/10.1375/aedp.28.2.75

Waters, L. (2012). Predicting job satisfaction: Contributions of individual gratitude and institutionalized gratitude. Psychology, 3, 1174-1176. http://dx.doi.org/10.4236/psych.2012.312A173

Williams, P., Kern, M. L., \& Waters, L. (2015). A longitudinal examination of the association between psychological capital, perception of organizational virtues and work happiness in school staff. Psychology of Well-Being, 5(1), 1-18. http://dx.doi.org/10.1186/s13612-015-0032-0

Wright, T. A., \& Bonett, D. G. (2007). Job satisfaction and psychological well-being as nonadditive predictors of workplace turnover. Journal of Management, 33(2), 141-160. http://dx.doi.org/10.1177/0149206306297582

Youssef, C. M., \& Luthans, F. (2007). Positive organizational behavior in the workplace. Journal of Management, 33(5), 774-800. http://dx.doi.org/10.1177/0149206307305562

Youssef, C. M., \& Luthans, F. (2011). Positive psychological capital in the workplace: Where we are and where we need to go. In K. M. Sheldon, T. B. Kashdan, \& M. F. Steger (Eds.), Designing Positive Psychology: Taking Stock and Moving Forward (pp. 351-364). New York: Oxford University Press. http://dx.doi.org/10.1093/acprof:oso/9780195373585.003.0023

Youssef-Morgan, C. M., \& Luthans, F. (2014). Psychological capital and well-being. Stress and Health, 31, 180-188. http://dx.doi.org/10.1002/smi.2623

Zajonc, R. B. (1968). Attitudinal effects of mere exposure. Journal of Personality and Social Psychology, 9(2p2), 1. http://dx.doi.org/10.1037/h0025848

Zanna, M. P., \& Rempel, J. K. (1988). Attitudes: A new look at an old concept. In D. Bar-Tal, \& A. W. Kruglanski (Eds.). The social psychology of knowledge. (pp. 315-334). New York, NY, US: Cambridge University Press. 